\title{
Effect of Design Ductility on the Progressive Collapse Potential of RC Frame Structures Designed to Eurocode 8
}

\author{
Mark Adom-Asamoah ${ }^{1, *}$, Nobel Obeng Ankamah ${ }^{2}$ \\ ${ }^{1}$ Department of Civil Engineering, Kwame Nkrumah University of Science and Technology, Kumasi, Ghana \\ ${ }^{2}$ Department of Civil Engineering, Sunyani Polytechnic, Sunyani, Ghana
}

Email address:

markadomasamoah@gmail.com (M. Adom-Asamoah), obeng86@hotmail.com (N. O. Ankamah)

\section{To cite this article:}

Mark Adom-Asamoah, Nobel Obeng Ankamah. Effect of Design Ductility on the Progressive Collapse Potential of RC Frame Structures Designed to Eurocode 8. American Journal of Civil Engineering. Vol. 4, No. 2, 2016, pp. 40-49. doi: 10.11648/j.ajce.20160402.11

\begin{abstract}
Progressive collapse is the cause of most structural failures around the world. The US General Service Administration (GSA) has presented guidelines for the assessment of the vulnerability of building structures to progressive collapse. It has been established in literature that the philosophy of ductility and redundancy used in seismic design is beneficial in resisting progressive collapse but not accounted for in these guidelines. The GSA methodology is particularly suited to seismic codes which allows for a constant member rotation but may be unsuitable to other codes that makes provision for ductility level. In this study, an investigation into the progressive collapse potential of RC framed structures designed to the seismic design code, EC 8, with varying design ground accelerations and ductility classes under different column loss scenarios was done. Based on the EC 8, a criteria for maximum plastic rotations and dynamic multiplies for progressive collapse analysis was proposed. These proposed criteria, together with the GSA criteria, were used to investigate the designed structures. The EC 8 criteria proved that buildings designed for higher ductilities yield at lower loads but undergo greater deformations and absorbs more energy to resist collapse. On the other hand, buildings designed for lower ductilities have higher yield loads but undergo lower deformations before collapse. Higher PGAs result in higher yield strengths but does not necessarily deformation capacity. This effect of ductility was not seen with the GSA criteria since a constant rotation capacity was recommended for all the buildings regardless of design ductility. It was also found that the removals of a corner column possess the greatest threat to progressive collapse on a building.
\end{abstract}

Keywords: Design Ductility, Progressive Collapse, RC Frames, Eurocode 8

\section{Introduction}

Progressive collapse is a phenomenon that involves the damage of a structural element resulting in the collapse of a disproportionately large part of the structure or the entire structure. Being a result of common conditions such as accidental impact, construction defects, structural overloads and failure of foundations, it is the cause of most structural collapse around the world (Wardhana and Hadipriono, 2003). The United States General Service Administration (GSA) and the Department of Defence (DoD) have presented practical guidelines (GSA, 2003 and DoD, 2005) for progressive collapse analysis of building. The basic technique of progressive collapse analysis of buildings known as alternative path method is adopted by both guidelines. This method involves the instantaneous removal of a load bearing member and its consequence on the ability of the modified structure to attain equilibrium. Currently, four methods of analysis namely linear static, linear dynamic, nonlinear static, and nonlinear dynamic are recommended for the alternate path method (Qazi et al., 2015, Patel and Parikh, 2013). Even though the nonlinear dynamic analysis procedure is believed to be the most accurate, the complexity of analysis and the extensive computing time involved do not lend itself suitable for design office use. Therefore, the nonlinear static (pushdown) analysis is still very relevant in investigating the collapse behaviour of a structure (Patel, 2014). As the lateral pushover analysis is widely used to evaluate structural properties such as yield stress, lateral stiffness, maximum lateral load resistance, and ultimate lateral displacement, it is expected that similar useful information may be obtained by the pushdown analysis for progressive collapse (Mohamed, 2015). 
Numerical studies by Tsi and Lin (2008) and laboratory experiments by Tsitos (2008) have shown that seismically designed RC and steel frame buildings have high resilience to progressive collapse. It is also known that a seismically designed structure relies on its ductility and redundancy properties to limit the damaged to the initially affected zones. As per the EC 8 provisions, seismic forces are dissipated by varying levels of damping energy or ductile behaviour. A structure or structural element is considered ductile if it undergoes large deformations beyond the yield point without breaking. It is worthy of note that in seismic engineering, ductility is expressed in terms of maximum available ductility possessed by a structure and the ductility demand of the seismic action. EC 8 has rules for construction to achieve the ductile behaviour modelled for predefined critical areas (Elghazouli, 2009). These in turn ensure that a preferred plastic behaviour is achieved instead of a brittle mode of failure (concrete shear, concrete crushing and reinforcement pull-out).

There are three levels of energy absorption, known as ductility classes, according to EC 8 . These ductility classes, coupled with levels of seismic design load ensure different seismic resistance levels by trading between available designs seismic forces and ductility demand (Fig. 1).

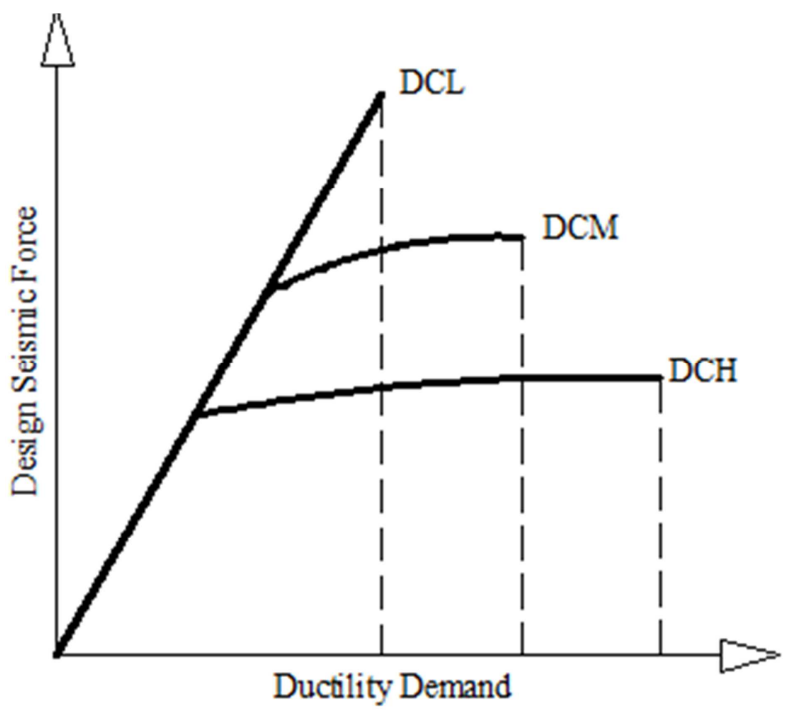

Figure 1. Variation of design seismic force with ductility demand.

These classes, defined by a behaviour factor $\mathrm{q}$, are as Ductility Class Low (DCL), Ductility Class Medium (DCM) and Ductility Class High (DCH). DCL does not require delayed ductility, but resistance to seismic loading is achieved through the strength capacity of the structures. The design case is inherently elastic $(\mathrm{q} \leq 1.5)$. DCM allows high level of ductility and there are responsive design demands $(1.5<\mathrm{q} \leq 4)$. DCH allows even higher levels of ductility with responsive strict and complicated design demands $(4.0<\mathrm{q} \leq 6.0)$.

The interpretation of the code requirements is that these three ductility classes are equivalent regarding the performance of the structure under the design seismic action
(Kappos and Penelis, 2010). It is expected that for a structure under the same design seismic force, whilst the design seismic lateral force increases from DCH to DCL, the damping energy (ductility) reduce from DCH to DCL (see Fig.1). This assures that the three classes are equivalent in terms of energy absorbed, which is measured as the area under the respective force-displacement curves. In order to achieve this energy equivalence, EC8 allows different rotation capacities for different ductility classes before failure.

The GSA guidelines recommend that a nonlinear progressive collapse analyses be performed with a maximum rotation of 0.035 radians for RC frames. Therefore, in the progressive collapse analysis of structures designed to EC 8, there is a disagreement between the EC8 and the GSA provisions. Different maximum plastic hinge rotations are required for the accurate prediction of the progressive collapse potential of structures based on the provisions of EC 8. In this study, the required maximum rotation capacities corresponding to the various EC8 ductility classes and their effect on the progressive collapse potential of EC8 designed buildings were investigated.

Again, according to the GSA the nonlinear static procedure requires a dynamic multiplier (DM) to account for dynamic (inertial) effects. The GSA recommends a constant DM of 2.0 , which is applied directly to the progressive collapse load combination. Marchis (2013) suggested that the values for DMs are affected by the ductility capacity of the structures. An investigation into the variation of DMs based the ductility class of the structure was also done in this study. The calculated DMs for the various structures were used in the analysis.

\section{Description of the Structure}

Six 11-storey reinforced concrete spatial frame models were designed to EC 8 with ground accelerations of $0.10 \mathrm{~g}$, $0.15 \mathrm{~g}$ and $0.25 \mathrm{~g}$ and varying ductility classes and hence behaviour factors. The values of the corresponding behaviour factors are shown in Table 1.

Table 1. Details of structural configurations.

\begin{tabular}{llll}
\hline $\begin{array}{l}\text { Structure } \\
\text { Reference }\end{array}$ & Design PGA $(\mathrm{g})$ & $\begin{array}{l}\text { Ductility } \\
\text { Class }\end{array}$ & Behaviour (q) Factor \\
\hline L0.10 & 0.10 & Low & 1.50 \\
H0.15 & 0.15 & High & 5.85 \\
M0.15 & 0.15 & Medium & 3.90 \\
L0.15 & 0.15 & Low & 1.50 \\
H0.25 & 0.25 & High & 5.85 \\
M0.25 & 0.25 & Medium & 3.90 \\
\hline
\end{tabular}

Each building had four bays in the $\mathrm{x}$-direction and three bays in the y-direction as shown in Fig. 2. The structures were regular in plan and elevation. They had uniform column spacing of $5.0 \mathrm{~m}$ giving an overall dimension of $20.0 \mathrm{~m}$ in the $\mathrm{x}$-direction and $5.0 \mathrm{~m}$ in the $\mathrm{y}$-direction giving an overall 
dimension of $15 \mathrm{~m}$. Storey height was $3.0 \mathrm{~m}$ for all floors giving a total building height of $33.0 \mathrm{~m}$ for all. All beamcolumn connections were modelled as fully rigid whilst the foundations were modelled as fixed. Table 2 shows the detailed description of the member section dimensions used in the models. All dimensions are in millimetres.

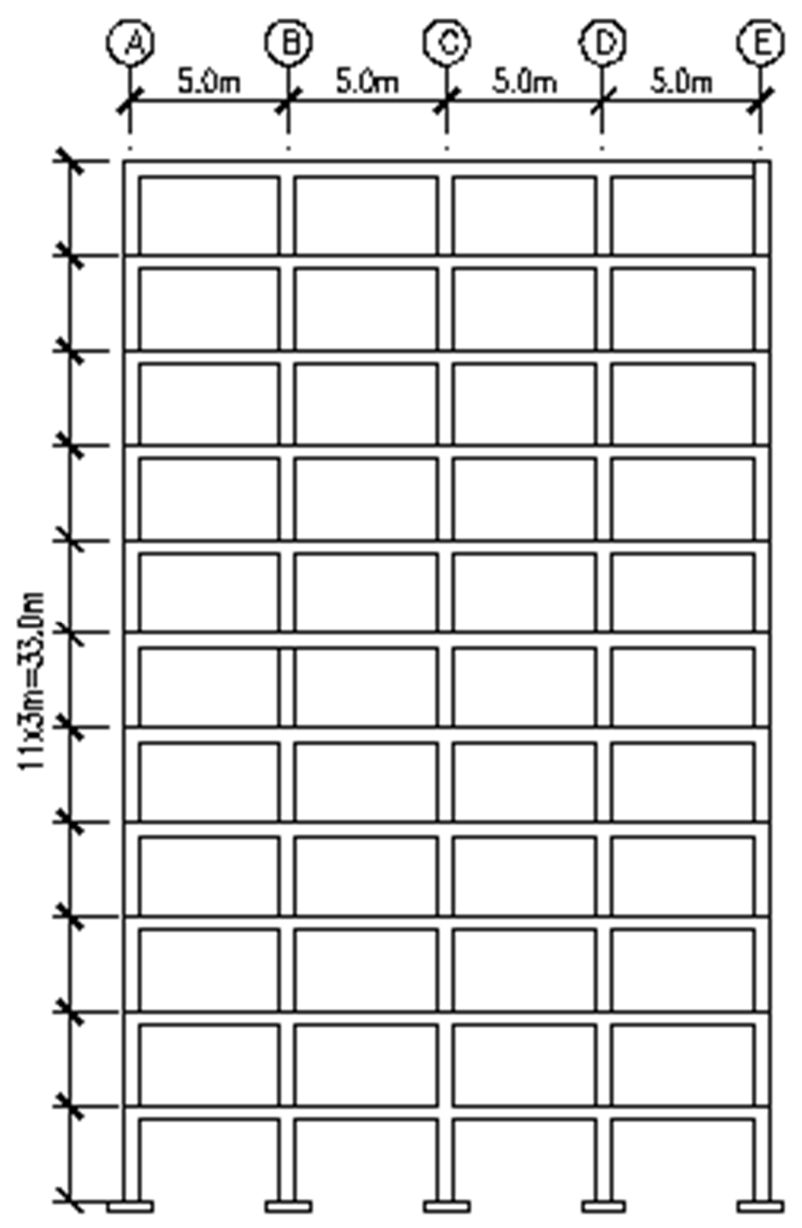

(a)

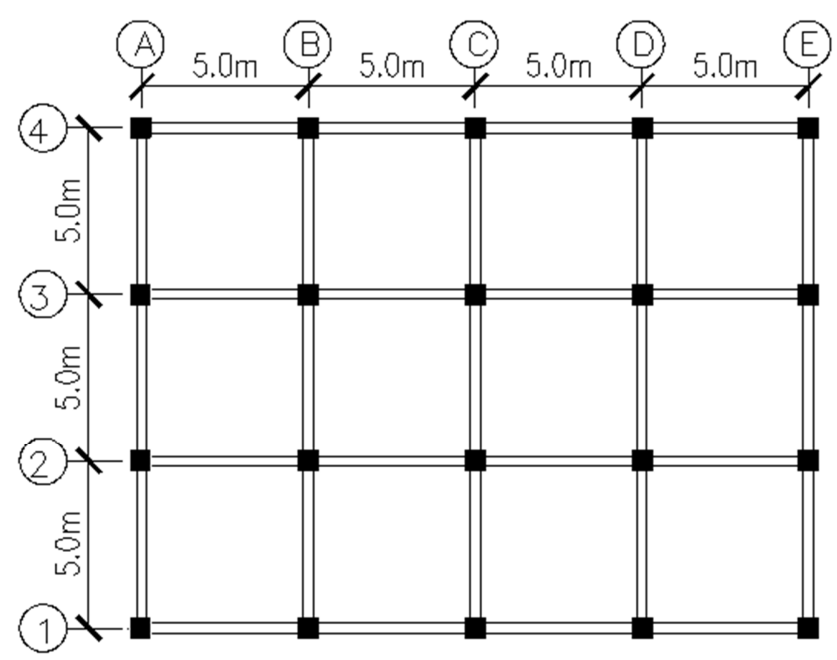

(b)

Figure 2. Plan and elevations of building.
Table 2. Member cross-section dimensions.

\begin{tabular}{lllll}
\hline \multirow{2}{*}{ Dimension } & \multicolumn{2}{l}{ Columns $(\mathbf{m m})$} & \multirow{2}{*}{ Beams (mm) } \\
\cline { 2 - 4 } & Internal & External & Corner & \\
\hline Height & 800 & 600 & 550 & 600 \\
Width & 800 & 600 & 550 & 300 \\
\hline
\end{tabular}

\section{Analysis Parameters}

\subsection{Rotation Capacity}

For progressive collapse analyses according to the GSA, the moment-hinge properties shown in Fig. 3 were used. The collapse point is represented as Point $\mathrm{C}$ on the curve represents and was assigned a rotation of $0.035 \mathrm{rad}$, as recommended by the GSA for RC frames. The slope from point $\mathrm{B}$ to $\mathrm{C}$ was taken as $10 \%$ of the elastic slope to accounts for strain hardening; the seismic code ASCE 41(2006) indicates that the slope should be taken as a small percentage between $0 \%$ and $10 \%$. Point D corresponds to the residual strength 0.2 of the ultimate strength. Since the GSA (2003) does not specify a value for point $\mathrm{E}$ as the failure limit, a value of 0.07 radians was considered as an average value (0.04 rad - $0.10 \mathrm{rad}$ ) given by the DoD (2009).

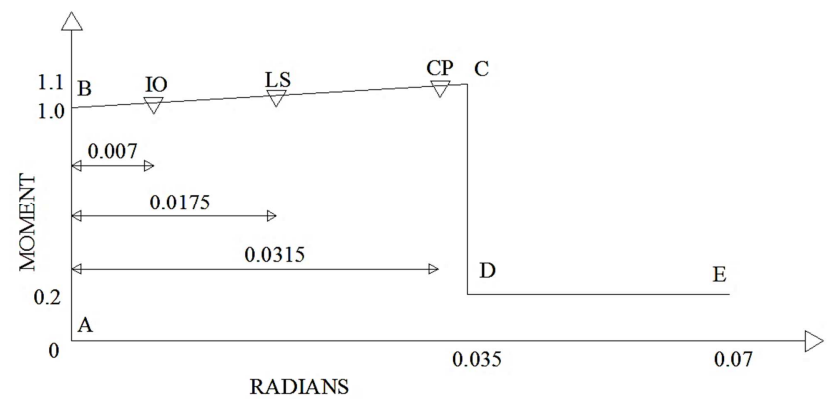

Figure 3. GSA Moment-rotation behaviour of hinges.

FEMA 356 (2000) performance levels were used to monitor the performance of the structures at different stages as load is applied. These include Immediate Occupancy (IO), Life Safety (LS), and Collapse Prevention (CP). For this study, these three points as $0.2 \Delta, 0.5 \Delta$ and $0.9 \Delta$ respectively based on provisions of FEMA 356 (2000) were defined. The Symbol " $\Delta$ " is the length of plastic hinge plateau.

Rotation capacities reflecting design ductility, according to EC 8, is illustrated in Fig. 4.
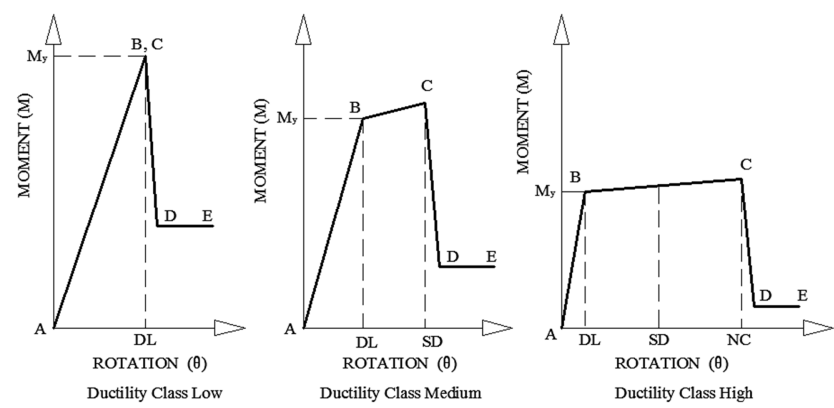

Figure 4. EC8 Moment-rotation behaviour of hinges. 
Thus, for high ductility class structures, members are detailed for the Near Collapse (NC) performance level with a rotation capacity $\theta_{u}$, expressed as

Medium ductility structures are detailed for the Significant Damage (SD) performance level, which allows for $75 \%$ of the ultimate rotation capacity $\theta_{\mathrm{u}}$. Ductility is not accounted for in Low ductility structures. Therefore, a member is considered failed when it deforms beyond the Damage Limitation (DL) performance level i.e. chord rotation equal to the yield rotation $\theta_{\mathrm{y}}$, expressed as

This EC 8 criterion was also considered for progressive collapse analysis. The rotation capacities were calculated by the program based on the seismic design results. The calculated average values for beams directly above the removed columns were as $0.007,0.026,0.019,0.009,0.026$ and 0.020 for L0.10, H0.15, M0.15, L0.15, H0.25 and M0.25 respectively.

\subsection{Columns Removal Scenarios}

The GSA guidelines specify four column loss scenarios in the assessment of the progressive collapse of a building as shown in Fig. 5. These are:

- Case 1: An exterior column near the middle of the short side of the building

- Case 2: An exterior column near the middle of the long side of the building

- Case 3: A column located at the corner of the building

- Case 4: A column interior to the perimeter

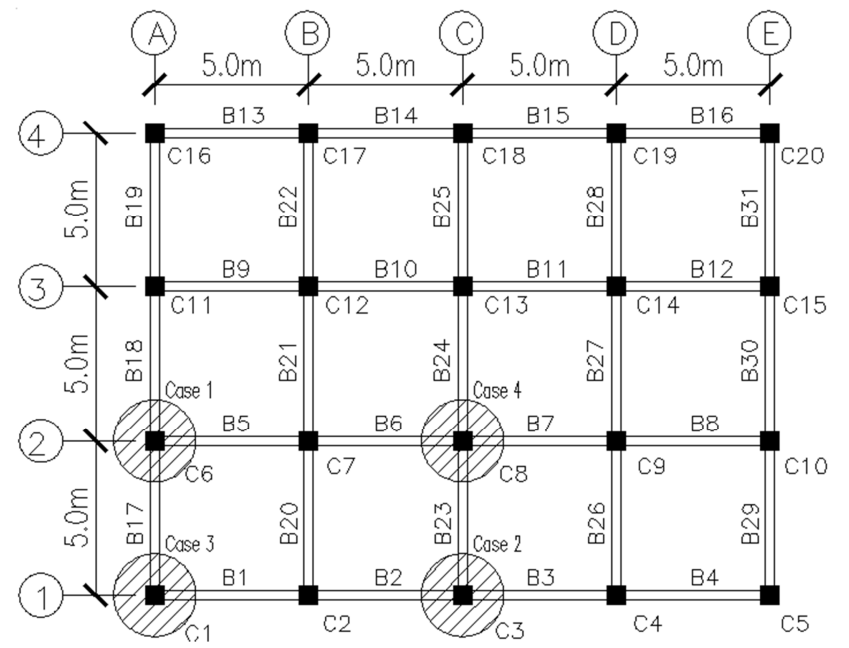

Figure 5. Typical plan of reinforced concrete structure.

\subsection{Dynamic Multiplier (DM)}

To determine the dynamic multipliers (DMs) for nonlinear static analysis, the nonlinear dynamic alternate path analysis was performed for all column loss cases under a load of $\left(\mathrm{G}_{\mathrm{k}}+0.25 \mathrm{Q}_{\mathrm{k}}\right)$. The maximum displacements at the points of column removal were noted. The nonlinear static "pushdown" analysis was also performed by setting the displacements achieved in the nonlinear dynamic analysis as the target displacements. The load factor at which the nonlinear static analysis produced the same displacement as the nonlinear dynamic analysis is noted as the dynamic multipliers (DM). The DMs determined for all the models in all four column-loss cases are presented in Table 3 .

It is observed that the DMs are typically less than the 2.0 provided by the GSA guidelines. Thus, the use of a load factor of 2.0 would overestimate the collapse vulnerability of the structures. In addition, the DMs vary with the different design parameters. They decrease with increasing design ductility class and decreasing peak ground acceleration (PGA

Table 3. DMs for all the models in all four column loss cases.

\begin{tabular}{lllll}
\hline Model & Case 1 & Case 2 & Case 3 & Case 4 \\
\hline H0.15 & 1.47 & 1.53 & 1.01 & 1.50 \\
L0.10 & 1.55 & 1.59 & 1.36 & 1.6 \\
H0.15 & 1.47 & 1.53 & 1.01 & 1.5 \\
M0.15 & 1.51 & 1.56 & 1.06 & 1.52 \\
L0.15 & 1.55 & 1.60 & 1.37 & 1.63 \\
H0.25 & 1.54 & 1.58 & 1.13 & 1.58 \\
M0.25 & 1.55 & 1.59 & 1.25 & 1.6 \\
\hline
\end{tabular}

\section{Analysis Methods}

\subsection{Nonlinear Dynamic Analysis (ND)}

In performing the ND analysis, a uniformly distributed gravity load of $(\mathrm{Gk}+0.25 \mathrm{Qk})$ was applied to the structure. The damping ratio used in the dynamic analysis was $5 \%$. Before the column removal, a nonlinear static analysis of the model was undertaken subjected to applied gravity load of $(\mathrm{Gk}+0.25 \mathrm{Qk})$. With the structure in static equilibrium, the target column was then removed instantaneously. In order to simulate the instantaneous removal of a column, the column was replaced with equivalent reaction obtained from a nonlinear static analysis of the building under the load of $(\mathrm{Gk}+0.25 \mathrm{Qk})$ applied to the whole structure (Fig. 6). The time for removal was set to $1.0 \mathrm{~ms}$. The response of the structure was observed until the structure became relatively stable.

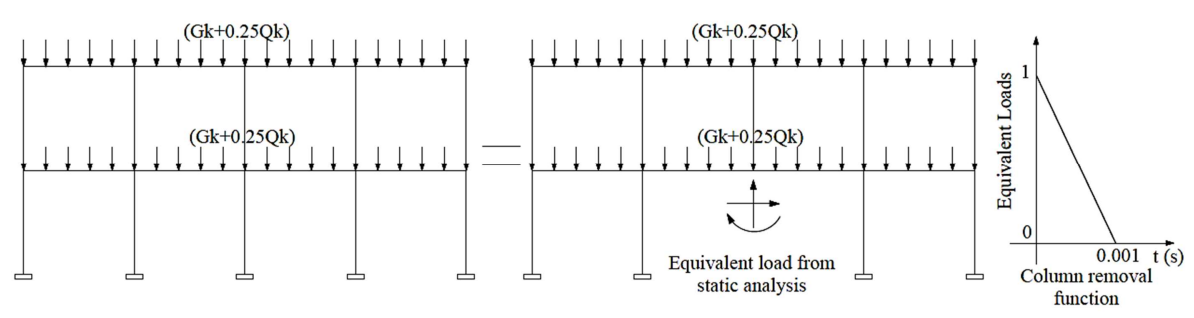

Figure 6. Definition of Nonlinear Dynamic load case. 
Plastic hinge were assigned to both ends of each member. Studies done by Choi and Kim (2011) and Yi et. al (2008) have shown that the progressive collapse of RC framed structures is controlled by the flexural failure of beams. Therefore, only flexural failure hinges were used here. The maximum plastic hinge rotations and displacements at the points of column removal during the analyses were noted and compared against the acceptable criteria of the GSA and EC 8. Vertical displacements at the points of column removal were monitored until the structure achieved relative stability.

\subsection{Nonlinear Static Analysis (NS)}

The NS procedure involves a stepwise increase of vertical loads, until a maximum amplified load of $\mathrm{DM}\left(\mathrm{G}_{\mathrm{k}}+0.25 \mathrm{Q}_{\mathrm{k}}\right)$ is reached or the structure collapses (Fig. 7). This method has the advantage of accounting for nonlinear effect without sophisticated hysteresis material model and time-consuming time-history analysis. Though it is unable to consider the dynamic effect due to the sudden loss of columns, it is useful in determining the elastic and failure limits of the structure (Taewan et al, 2009).

In this study, the displacement controlled pushdown analysis was carried out by increasing the applied load to increase the vertical displacement at the location of the removed column until collapse. The stepwise load increase was only applied on the bay with a lost column since load amplification due to inertia would directly affect this bay. A constant unamplified load of $\left(\mathrm{G}_{\mathrm{k}}+0.25 \mathrm{Q}_{\mathrm{k}}\right)$ was applied in the other bays to ensure a more accurate prediction of the dynamic effect (Taewan et al, 2009). For easier analysis and comparison of results for different models and column loss locations, the base shear was replaced by a load factor. The load factor at any step was determined as the ratio of the base reaction at that step to the base reaction at a load of $1.0\left(\mathrm{G}_{\mathrm{k}}+0.25 \mathrm{Q}_{\mathrm{k}}\right)$.
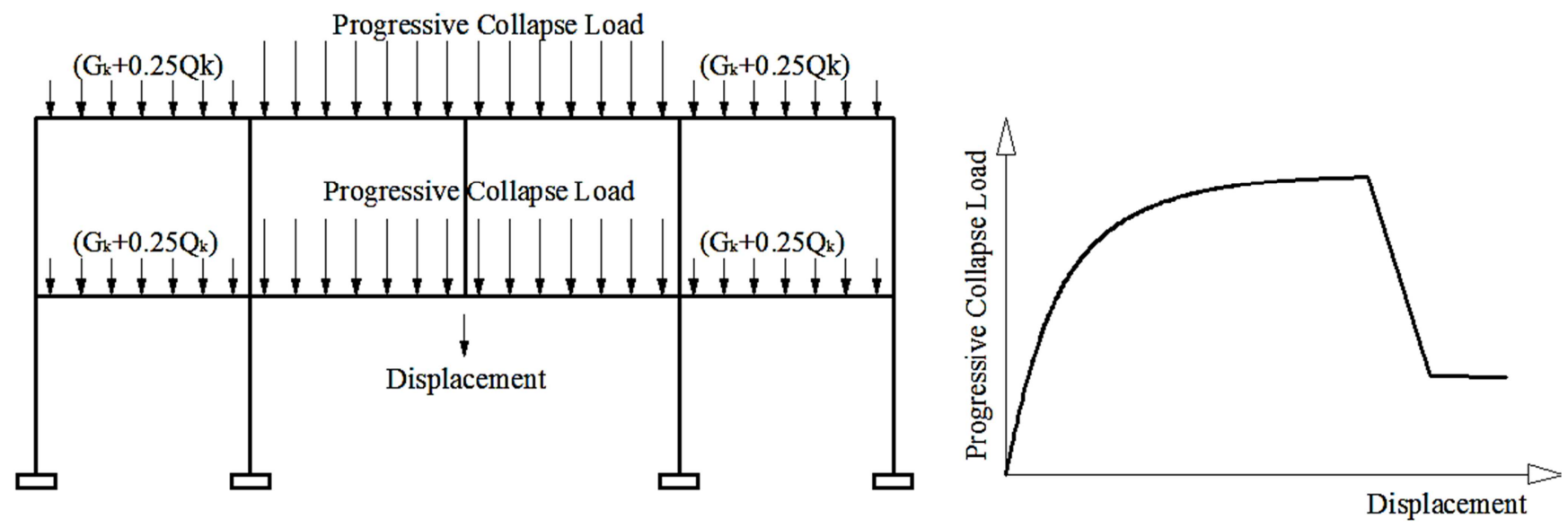

Figure 7. Definition of Nonlinear Static load case.

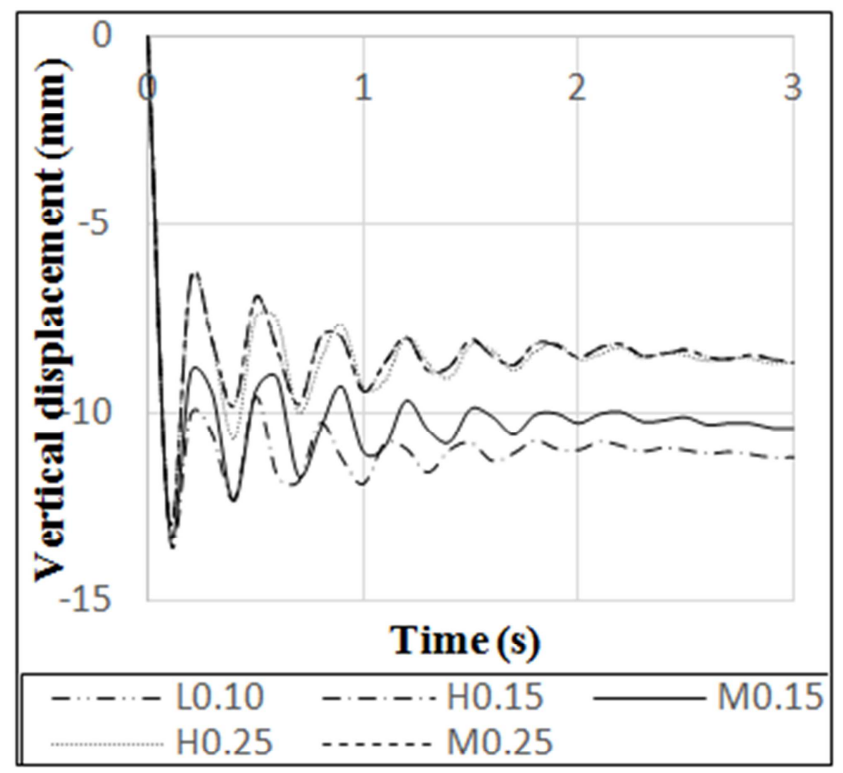

(a) GSA

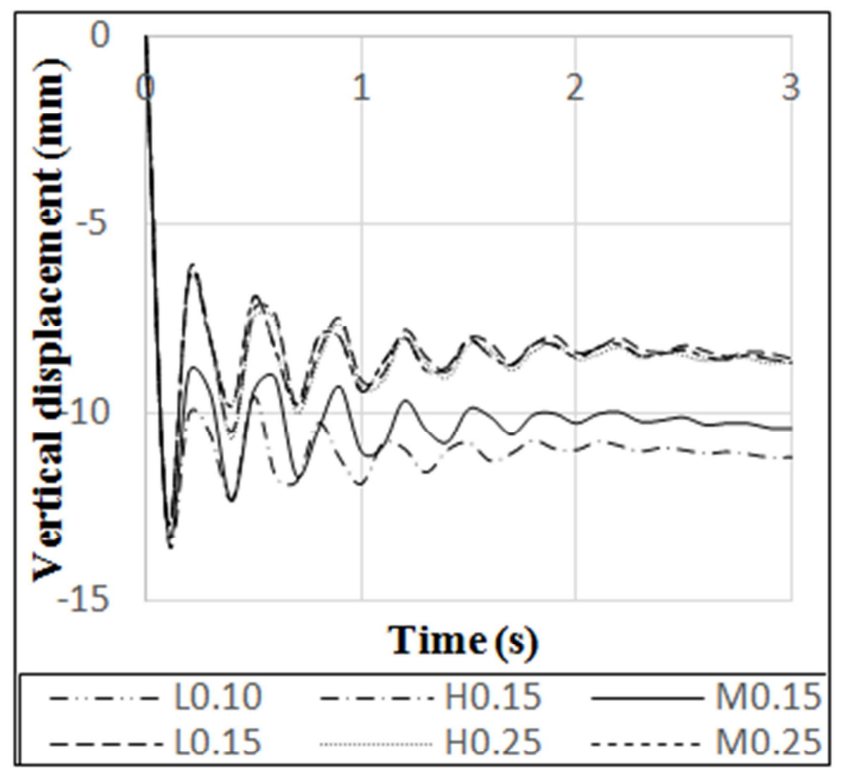

(b) EC8

Figure 8. Vertical displacement history for Case 1. 


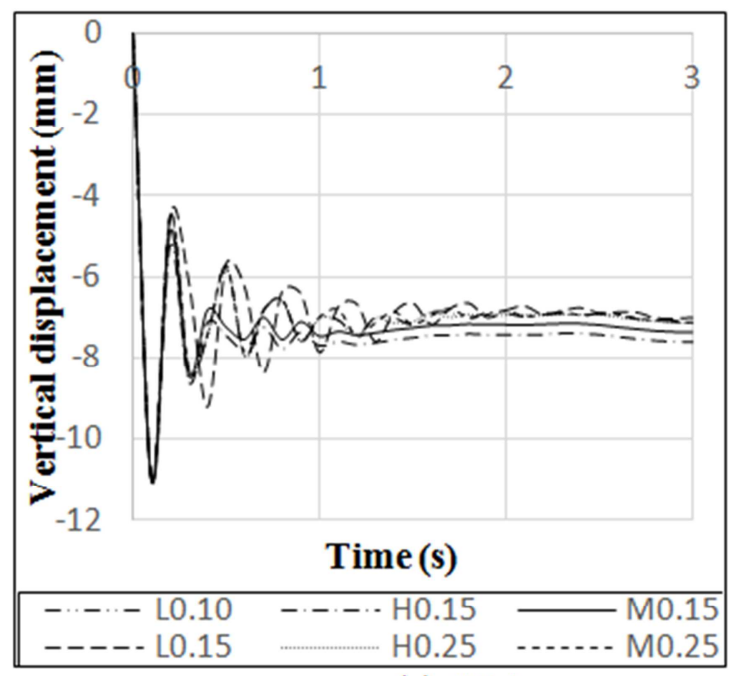

(a) GSA

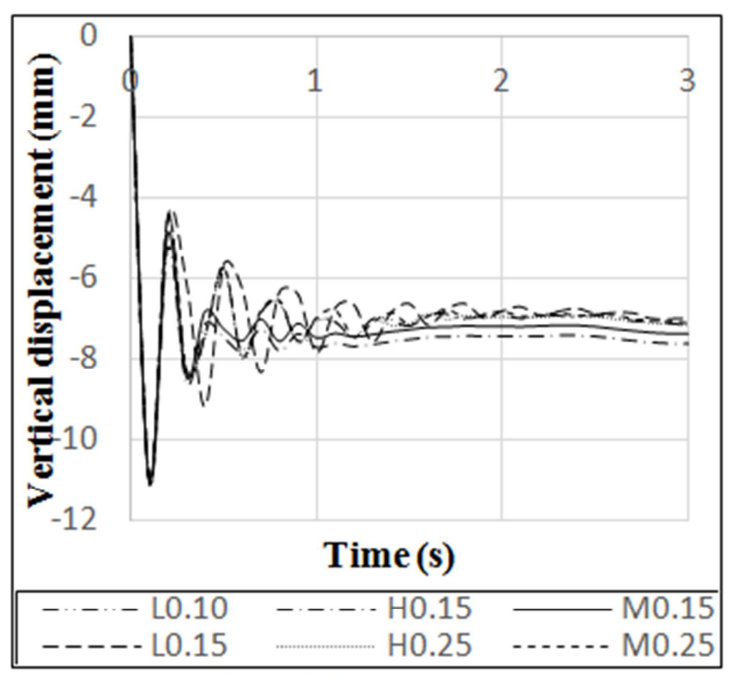

(b) EC8

Figure 9. Vertical displacement history for Case 2.

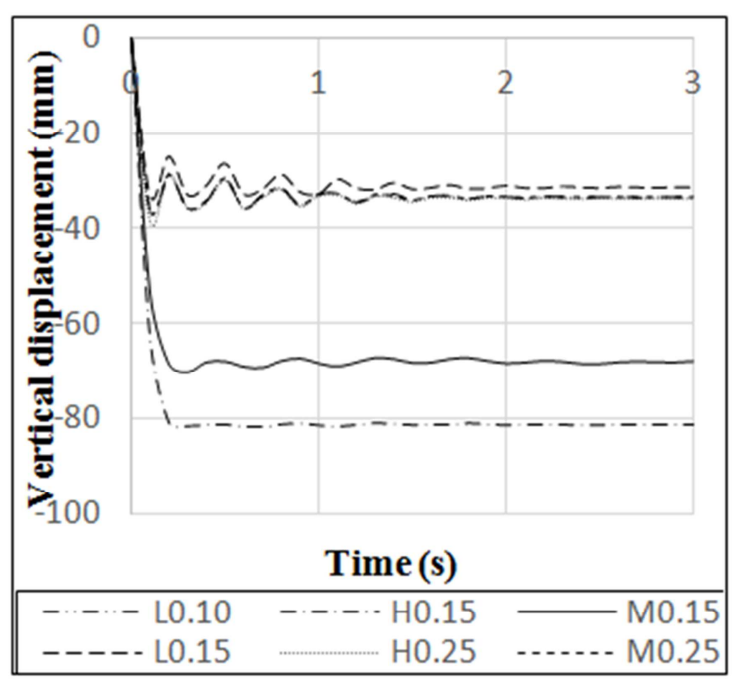

(a) GSA

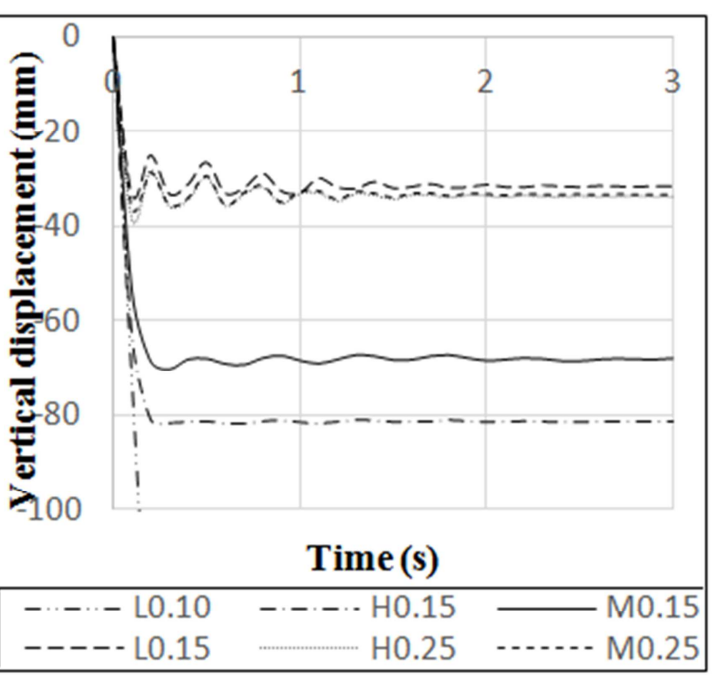

(b) EC8

Figure 10. Vertical displacement history for Case 3.

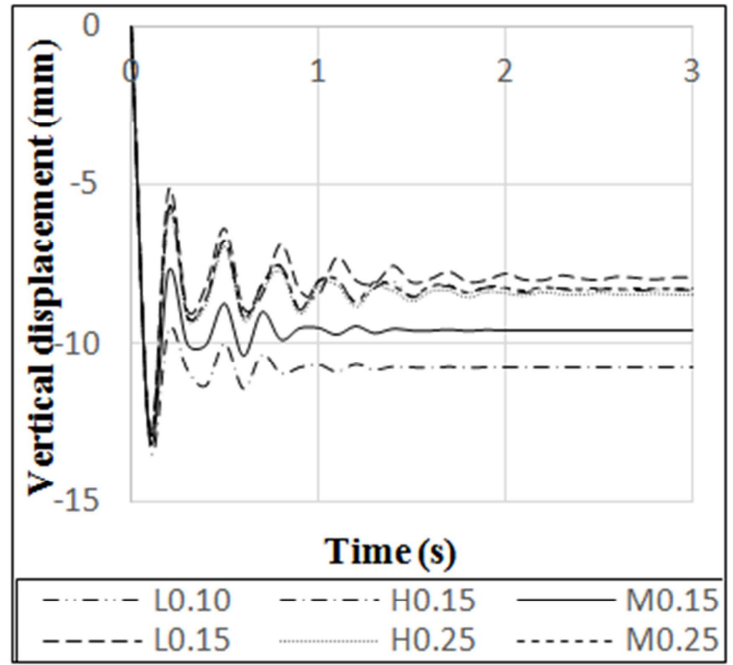

(a) GSA

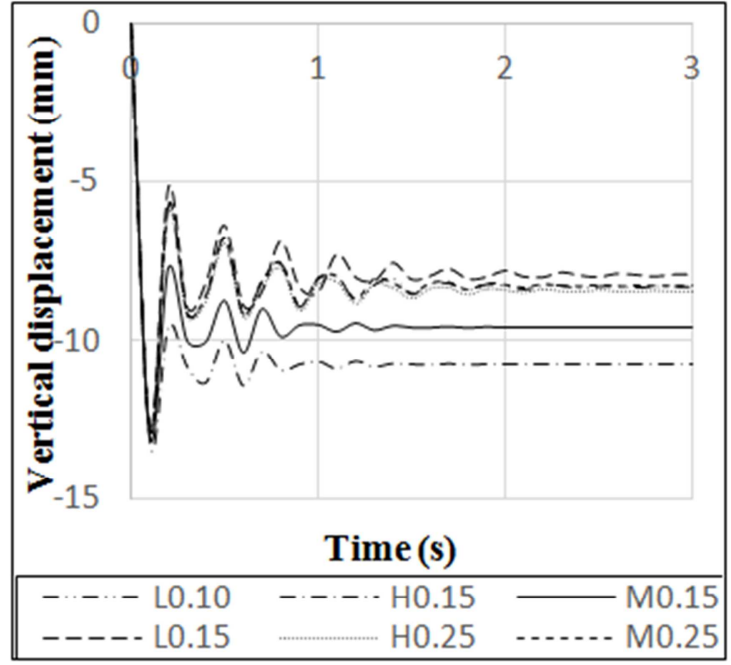

(b) EC8

Figure 11. Vertical displacement history for Case 4. 


\section{Discussion of Results}

\subsection{Nonlinear Dynamic Analysis}

Fig. 8-11 shows a comparison of the vertical displacements at the points of column removal with time for the GSA and EC8 methods. The maximum and final vertical displacements at the points of column removal are presented in Table 4.

The observed patterns of displacements were the same for both the GSA and the EC 8 methods except for the removal of a corner column (Case 3 ) from model L0.10. In all damage cases, vertical displacements peaked at approximately 0.11 seconds. Vibrations phased out gradually in different times. It was also observed that models designed with higher ductilities stabilized much earlier than models with lower ductilities. This is due to the early formation of plastic hinges in the beams, detuning the structures by elongating the period and consequently damping. The gradual stabilization of the vibration suggests low damping.

From the GSA analysis, plastic hinges developed in all models. However, all hinges rotations were all less than 0.035 radians. Collapse was therefore not experienced in any buildings. From the EC8 method, displacement at the point of column removal was infinite in the instance of the loss of a corner column (Case 3) from model L0.10. This indicates that the frame had failed under the dynamic load. The maximum displacement recorded for this instance by the GSA method was $36.31 \mathrm{~mm}$ whereas the maximum allowed was $175 \mathrm{~mm}$ (corresponding to a rotation capacity of 0.035 radians), hence the structure did not collapse. In the EC8 method, maximum allowed displacement was $35 \mathrm{~mm}$ (corresponding to a rotation capacity of 0.007 radians); hence, the structure collapsed before the displacement of $36.31 \mathrm{~mm}$ could be achieved. Collapse was not observed in any other building.

The generally higher displacements observed in Case 3 could be attributed to the fact that this case had the highest redistribution of axial loads. In this case, only two columns adjoin the removed column, therefore having percentageredistributed loads of $49.9 \%$ and $50.0 \%$ as shown in Table 4 . It is worthy of note that Cases 1,2 and 4 all have a minimum of three columns immediately surrounding the removed column.

Table 4. Displacements from Nonlinear Dynamic Analysis $(\mathrm{mm})(*=$ Failed $)$.

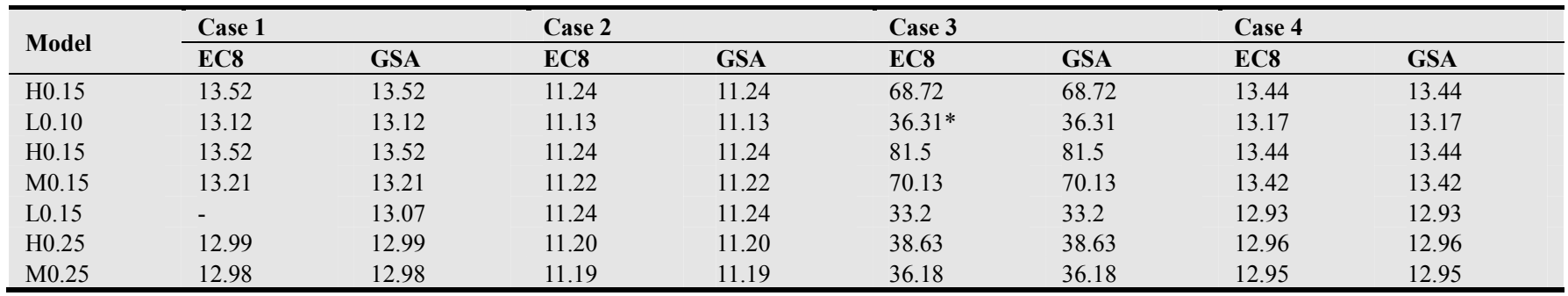

It must be noted that the observation from the proposed EC 8 is contrary to that made from the GSA analysis. This is because, GSA permits plastic rotation up to 0.035 radians regardless of the ductility class and design parameters of the structure. This demonstrates that the GSA method overestimates the progressive collapse resistance of structures designed for low ductility. In this damage case, the other models were found resilient to progressive collapse since the plastic hinge rotations fell below the corresponding performance threshold.

\subsection{Nonlinear Static Analysis}

The vertical displacement and corresponding vertical loads for all the buildings are plotted in Figures 12 - 15 for the various column loss scenarios. The collapse resistance of a building was as its ability to carry the ultimate load of $\mathrm{DM}\left(\mathrm{G}_{\mathrm{k}}+0.25 \mathrm{Q}_{\mathrm{k}}\right)$ before collapse. The maximum load factors for the models under the various column loss scenarios for both GSA and EC8 methods are presented in Table 6.

When a corner column was removed (Case 3 ), only model L0.15 was able to resist collapse as per the GSA method, with a load factors of 2.07. All the other models failed at load factors of 1.30, 1.16, 1.34, 1.32 and 1.42 for models L0.10, H0.15, M0.15, H0.25 and M0.25 respectively. Progressive collapse is therefore expected in these models for Case 3. For the EC8 method, only model L0.10 failed before the ultimate load was reached. Progressive collapse is therefore expected here. All other buildings were found resilient.

When a column was removed from a location interior to the perimeter (Case 4), model H0.15 failed under the loading for the GSA method, however the EC 8 method did not find any building venerable to progressive collapse in this case. This is because, even though the EC 8 criteria had lower plastic hinge rotation capacities, it also had lower DMs.

From the GSA load-displacement curves (Figures 12-15) and Table 5, it is observed that the resistance to progressive collapse of the structures increased with PGAs and lower ductility classes. This is because structures with higher PGAs and lower ductility classes had the highest amount of reinforcement from the seismic design and the GSA analysis is only based on strength and not ductility. Thus, the increase and decrease in ductility capacity with higher and lower design ductility classes was not accounted for.

From the EC 8 curves, it is observed that the structures resisted progressive collapse by two main mechanisms. These are strength and ductility. Low ductility class models had an advantage of high strength and therefore had higher yield loads and ultimately higher collapse loads. High 
ductility models yielded at lower loads, but were able to undergo relatively higher deformations, enabling them to absorb more energy and prevent collapse. This indicates that assessing structures design for different ductility with the same plastic rotations will result in overestimating the

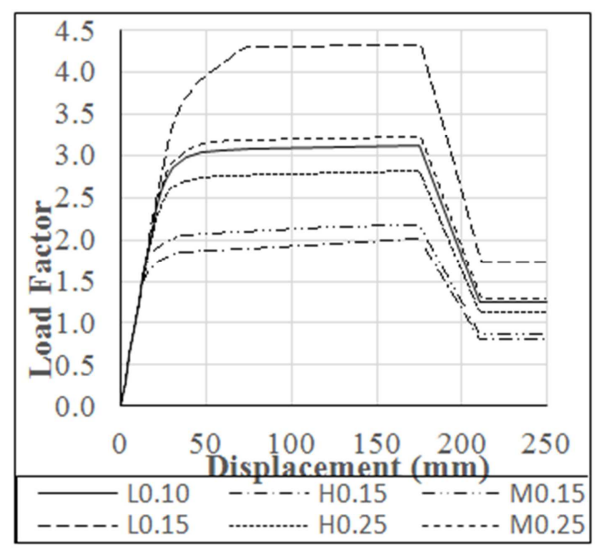

(a) GSA resistance of the low ductility buildings or underestimating the resistance of the high ductility buildings. In addition, the conclusion that designing at low ductility increases the structures resistance to collapse from other studies (Ioani et al (2007), Ioani and Cucu (2010)).

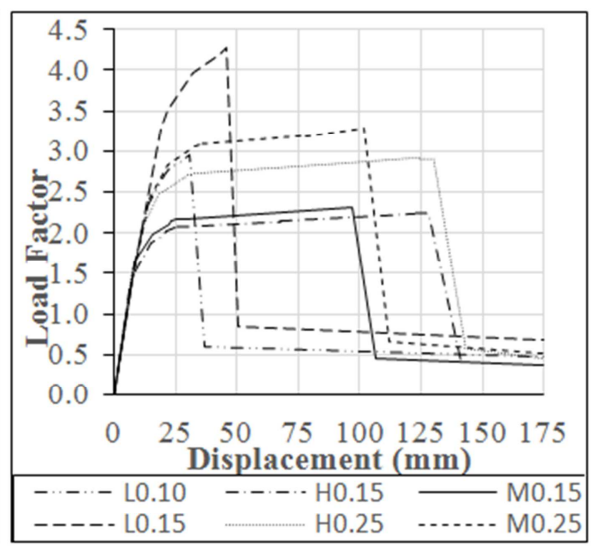

(b) $\mathrm{EC} 8$

Figure 12. Load-displacement relations for Case 1.

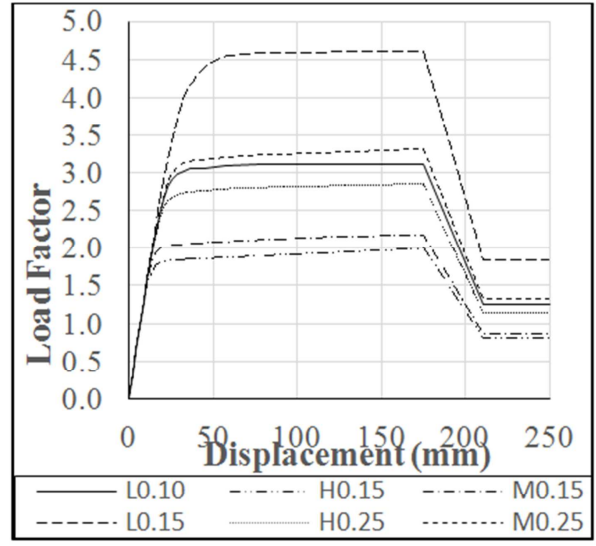

(a) GSA

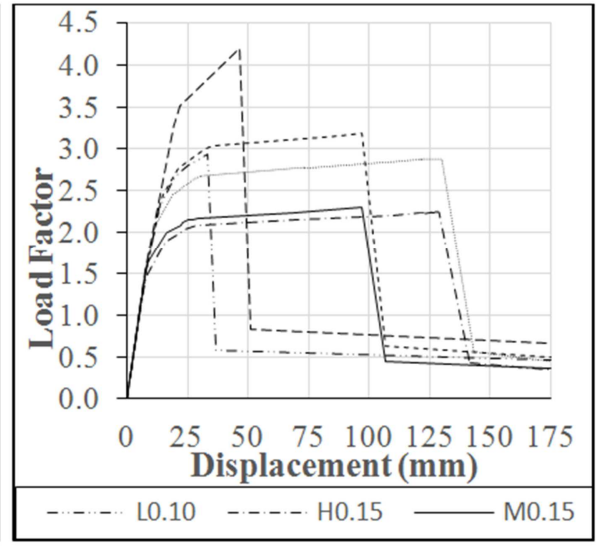

(b) EC8

Figure 13. Load-displacement relations for Case 2.

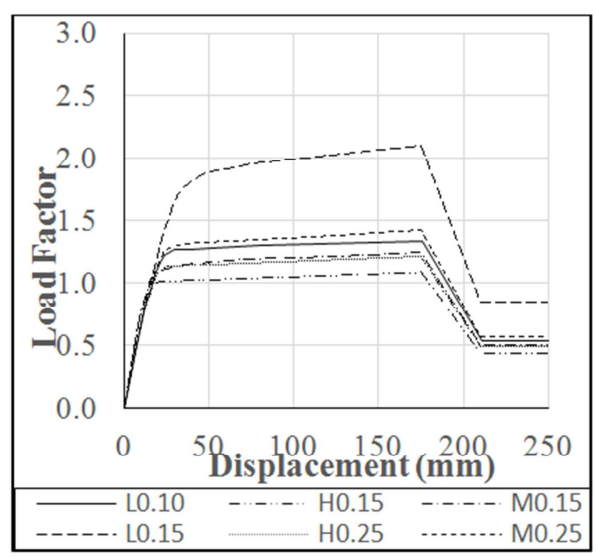

(a) GSA

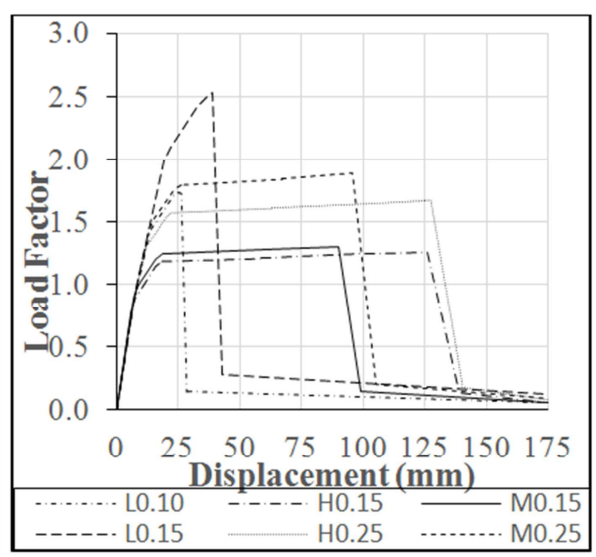

(b) EC8

Figure 14. Load-displacement relations for Case 3. 


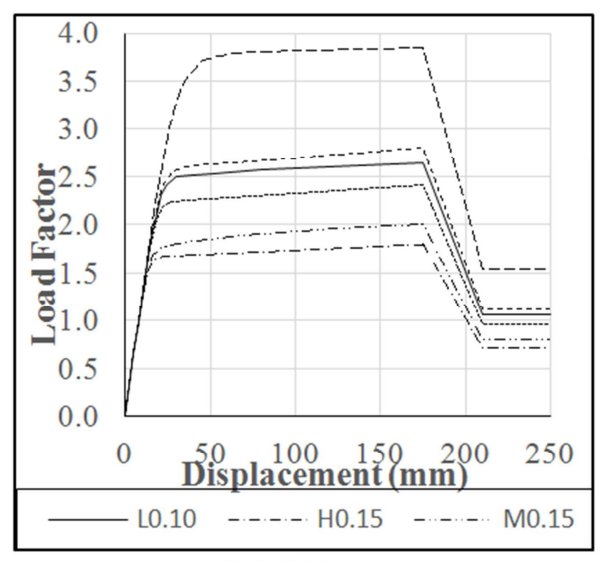

((a) GSA

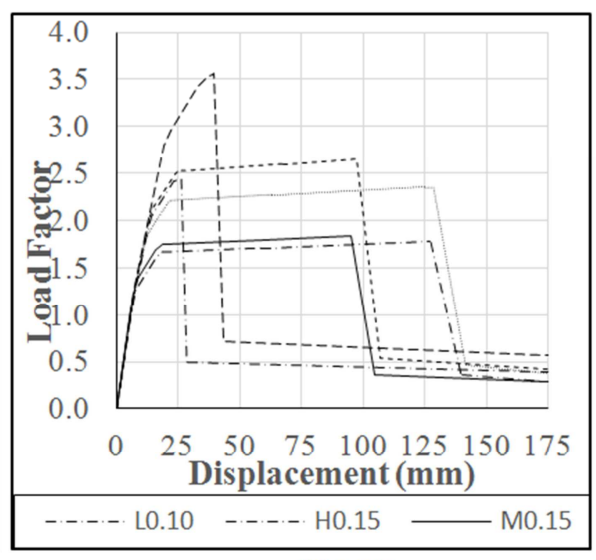

(b) EC8

Figure 15. Load-displacement relations for Case 4.

Table 5. Maximum load factors $(*=$ Failed $)$.

\begin{tabular}{lllllllll}
\hline \multirow{2}{*}{ Model } & Case 1 & \multicolumn{3}{c}{ Case 2 } & & Case 3 & \multicolumn{3}{c}{ Case 4 } \\
\cline { 2 - 9 } & EC 8 & GSA & EC 8 & GSA & EC 8 & GSA & EC 8 & GSA \\
\hline L0.10 & 2.96 & 3.08 & 2.93 & 3.12 & 1.35 & $1.30^{*}$ & 2.44 & 2.57 \\
H0.15 & 2.24 & 2.13 & 2.23 & 2.17 & $1.10^{*}$ & $1.16^{*}$ & 1.77 & 2.15 \\
M0.15 & 2.32 & 2.22 & 2.30 & 2.22 & 1.15 & $1.34^{*}$ & 1.84 & 2.04 \\
L0.15 & 4.28 & 4.35 & 4.19 & 4.59 & 2.21 & 2.07 & 3.56 & 3.81 \\
H0.25 & 2.91 & 3.12 & 2.87 & 3.22 & 1.46 & $1.32^{*}$ & 2.35 & 2.61 \\
M0.25 & 3.29 & 3.41 & 3.18 & 3.42 & 1.64 & $1.42^{*}$ & 2.65 & 2.80 \\
\hline
\end{tabular}

\section{Conclusion}

The various analyses carried out in this study came up with some major conclusions as elaborated below:

- The maximum plastic rotations required for nonlinear analysis vary according to the seismic design parameters. EC 8 allows rotations up to the Damage Limitation (DL), Significant Damage (SD) and Near Collapse (NC) performance levels for buildings designed for Low, Medium and High ductility classes respectively. The maximum allowed rotations also increased with design ductility and PGA. Therefore, the constant rotation capacity of 0.035 radians provided by GSA (2003) for all structures is inaccurate. This demonstrates the effect of seismic design on progressive collapse and disproves the assertion made by many researchers that buildings designed to lower ductility classes better resist progressive collapse.

- For the EC 8 nonlinear static method, different DMs were determined for all instances of collapse. It was shown that the required DMs for the nonlinear static method were lower than that for linear static method and also less than 2.0. They ranged from 1.22 to 1.63 . This indicates that the use of DMs of 2.0 overestimated the demand on the structures in progressive collapse analysis.

- The location of lost column also influenced the progressive collapse susceptibility of the building. The vulnerability of all the buildings was similar in Case 1, 2 and 4. All the buildings were found most vulnerable when a corner column was removed (Case 3). It is therefore recommended that based on this limited study and other research works, the progressive collapse analysis on regular medium storey $\mathrm{RC}$ frame buildings could be limited to the case 3 column removal scenario.

\section{References}

[1] ASCE-41, (2006): "Seismic Rehabilitation of Existing Buildings", American Society of Civil Engineers, Reston, VA, USA.

[2] Choi H, Kim J, (2011): "Progressive collapse-resisting capacity of RC beam-column sub-assemblage", Magazine of Concrete Research, Vol. 63, No.4.

[3] DOD (2005): "Design of building to resist progressive collapse". Unified Facilities Criteria (UFC) 4-023-03, Department of Defence, USA.

[4] Elghazouli A, (2009): "Seismic Design of buildings to Eurocode 8", Spon Press, London, United Kingdom.

[5] EN 1998 (2004): Eurocode 8: "Design of structures for earthquake resistance", European Committee for Standardization.

[6] FEMA 356 (2000): "Prestandard and Commentary for the Seismic Rehabilitation of Buildings", Federal Emergency Management Agency, Washington, USA.

[7] GSA (2003): "GSA Progressive Collapse Analysis and Design Guidelines for New Federal Office Buildings and Major Modernizations Projects", General Services Administration, USA. 
[8] Ioani A. M, Cucu H. L, (2010): "Resistance to progressive collapse of RC structures: principles, methods and designed models", Computational Civil Engineering 2010, Iasi, Romania.

[9] Ioani A. M, Cucu H. L, Mircea C (2008): "Seismic Design vs. Progressive Collapse: A Reinforced Concrete Framed Structure Case Study", Innovation in Structural Engineering and Construction.

[10] Kappos A, Penelis G. G, (2010): "Earthquake resistant concrete structures", CRC Press, pp607.

[11] Marchis A. G, Moldovan T. S, Ioani A. M, (2013): “The influence of the seismic design on the progressive collapse resistance of mid-rise RC framed structures", Acta Technica Napocensis: Civil Engineering \& Architecture Vol. 56, No. 2.

[12] Mohamed O. A. (2015): "Calculation of load increase factors for assessment of progressive collapse potential in framed steel structures", Case studies in Structural Engineering, Vol 3.

[13] Patel B. R (2014): "Progressive collapse analysis of RC Buildings using Nonlinear Static and Nonlinear Dynamic Method", International journal of Emerging Technology and Advanced Engineering, Vol 4(9).
[14] Patel PV, Parikh RD (2013), "Various procedures for progressive collapseanalysis of steel framed buildings", The IUP Journal of Structural Engineering, 6, p17-31.

[15] Qazi AU, Majid A, Hameed A, Ilyas M (2015): "Nonlinear progressive collapse analysis of RC frame structure", Pak. J. Engg. And Applied Science, 16, p121-132.

[16] Taewan K. Jinkoo K, Junhee P. (2009): "Investigation of Progressive Collapse-Resisting capability of Steel Moment Frames Using Push-Down Analysis”, Journal of Performance of Constructed Facilities, Vol. 23, No. 5.

[17] Tsitos A, Mosqueda G, Filiatrault A, Reinhorn A. M., (2008): "Experimental investigation of progressive collapse of steel frames under multi-hazard extreme loading", The 14th World Conference on Earthquake Engineering, October 12-17, 2008, Beijing, China.

[18] Wardhana K, Hadipriono F. C, (2003): "Study of Recent Building Failures in the United States", Journal of Performance of Constructed Facilities, Volume 17, No. 3.

[19] Yi W. J, He Q. F, Xiao Y, Kunnath S. K, (2008): “Experimental study on Progressive Collapse-resistant behaviour of reinforced concrete frame structures", ACI Structural Journal, Vol.105, No.4, pp.433-438. 